\title{
Economic Value of Atopic Dermatitis Prevention via Partially- hydrolyzed Whey-based Infant Formula (PHF-W) Use in High-risk, Non-exclusively Breastfed, Indonesian Urban Infants: Results of a Cost-effectiveness Model
}

Received, 30 October 2018 Accepted, 28 November 2018

Link to DOI:

10.25220/WNJ.V02.i2.0008

Journal Website: www.worldnutrijournal.org
Marc F Botteman ${ }^{1}$, Zakiudin Munasir ${ }^{2}$, Astrid W Sulistomo ${ }^{3}$, Erica G Horodniceanu ${ }^{1}$, Abhijeet J. Bhanegaonkar, ${ }^{1}$ Xiang $\mathrm{Ji}^{1}$, Wing Yu Tang, ${ }^{1}$ Ray Wagiu Basrowi, ${ }^{4 *}$ Patrick Detzel ${ }^{5}$

1. Pharmerit International, Bethesda, MD,USA

2. Division of Allergy and Immunology, Department of Child Health, Cipto Mangunkusumo

Hospital, Faculty of Medicine, Universitas Indonesia, Jakarta Pusat, Indonesia

3. Department of Community Medicine, Faculty of Medicine, Universitas Indonesia, Jakarta Pusat, Indonesia

4. Nestlé Nutrition Institute, Indonesia

5. Nestlé Research Center, Lausanne, Switzerland

\begin{abstract}
Introduction Early nutritional intervention with partially-hydrolyzed whey-based formula (PHF-W) instead of standard cow's milk formula (CMF) has been found to reduce the risk of atopic dermatitis (AD) development in non-exclusively breastfed infants with familial heredity of AD.

Objective To estimate the 6-year economic impact of this nutritional intervention in non-exclusively breastfed Indonesian urban infants with family history of $A D$.

Methods A mathematical model simulated AD incidence and burden of using PHF-W vs. CMF in the target population from birth to age 6 . The model integrated literature, current cost and market catalogues, and expert clinician opinion. Modelled outcomes included AD risk, time spent post-AD diagnosis, days without flare, quality-adjusted life-years, and costs.

Results Using PHF-W instead of CMF resulted in an estimated absolute $14 \%$ (95\% CI: 4\%, 23\%) AD risk reduction, a 0.69 year $(95 \% \mathrm{Cl}: 0.26,1.13)$ per-child reduction in time spent post-AD diagnosis, a $38(95 \% \mathrm{Cl}: 12,67)$ increase in days without AD flare, and a 0.046 gain in quality-adjusted lifeyears. The AD-related 6-year cost estimates when feeding high-risk urban infants with PHF-W were Indonesian Rupiah (IDR) 8,695,057 (95\% Cl: IDR 4,519,447, IDR13,995,605) and IDR13,139,569 (95\% Cl: IDR 7,098,794, IDR 19,216,068) per child, respectively, resulting in a net per-child difference of IDR 4,444,512 (95\% Cl: IDR1,893,080, IDR 8,557,946) favoring PHF-W.

Conclusion PHF-W for the first 17 weeks of non-exclusively breastfed Indonesian urban infants with a hereditary risk of AD demonstrated a reduction in AD incidence, increased days without flare, and increased quality-adjusted life-years and net cost reductions.
\end{abstract}

Keywords cost effectiveness; atopic dermatitis; infant formula; hydrolyzed formula; Indonesia

\section{Corresponding author:}

Ray Wagiu Basrowi, MD, MKK

Nestlé Nutrition Institute, Indonesia

PT Nestlé Indonesia

Perkantoran Hijau Arkadia; Jl. Let Jen TB Simatupang

Kav. 88

Jakarta 12520, INDONESIA

ray.basrowi@id.nestle.com

ray.basrowi@gmail.com

\section{Introduction}

Atopic dermatitis (AD) is a common inflammatory skin disorder that most commonly occurs during infancy. ${ }^{1,2}$ Often a chronic disorder, AD imposes a substantial economic and quality of life (QoL) burden on children, caregivers, and society. ${ }^{3-7}$ 
In Indonesia, $\mathrm{AD}$ incidence was $11 \%$ among infants aged 0-4 months. ${ }^{8}$ Available estimates of the annual cost of AD per child in Asia range from \$199 in Thailand $^{9}$ to USD3,522 (direct cost only: USD1,253) in patients receiving care at allergy clinic in South Korea ${ }^{10}$ (all figures inflated to 20122013 and converted to USD).

$\mathrm{AD}$ is affected by various genetic, immunologic, and environmental factors. For example, in Indonesia, infants with family atopy were over 22 times as likely of developing $\mathrm{AD}$ compared to infants with no family history. ${ }^{8}$ Exposure to allergens, such as proteins within standard cow's milk formula (CMF), can increase the risk of AD in infants. Despite recommendations to exclusively breastfeed infants in the first 6 months of life, ${ }^{11-13}$ formula feeding with CMF is often used as a nutritional supplement or replacement for breast milk. In high-risk infants with first degree heredity of $\mathrm{AD}$ (i.e., those with $\geq 1$ parent or sibling with history of allergic disease $\left.{ }^{14-16}\right)$, such exposure to cow's milk may result in a greater risk of $\mathrm{AD}$ development.

Partially or extensively hydrolyzed formulas are two alternative protein sources that have been shown to reduce the risk of $\mathrm{AD}$ and other allergies ${ }^{17,18}$ compared to CMF in these high-risk infants. ${ }^{14,19,20}$ In particular, the German Infant Nutritional Intervention (GINI) trial found that nonexclusively breastfed infants with atopic heredity randomized to whey-based partially hydrolyzed formulas (PHF-W) for their first 4 months experienced a lower cumulative incidence of $\mathrm{AD}$ relative to CMF 6 years following birth $(27.4 \%$ vs. $39.1 \%$, adjusted RR $=0.64 ; 95 \% \mathrm{CI}: 0.48-0.86) .{ }^{14} \mathrm{On}$ the basis of such data, several national and international allergy organizations have suggested hydrolyzed formulas as an allergy risk reduction strategy for these high-risk infants. ${ }^{16,21-23}$ As demonstrated previously, the potentially higher costs of PHF-W relative to CMF during the 17-week interventional period should be partially offset by the direct and indirect cost savings and QoL improvements associated with the reduction in $\mathrm{AD}$ incidence in this high-risk population. ${ }^{24-31}$

Using health economic modeling techniques that combine data from the GINI study (the largest comparative trial of infant formula in high risk infants), ${ }^{14}$ experts opinions, and local cost data, this study estimated the clinical and economic impact of an intervention consisting in feeding high-risk urban
Indonesian infants with PHF-W instead of CMF for the first 17 weeks of life. The analysis was limited to the urban population because it is considered most likely to be consuming the infant formula evaluated herein.

\section{Methods}

\section{Overview}

Mathematical modeling (i.e., Markov cohort techniques - an extension of life table analysis) $)^{32,33}$ were used to compare costs and outcomes associated with AD development over time among those using PHF-W vs. CMF from birth to 17 weeks of life in non-exclusively breastfed urban Indonesian infants with first degree atopic hereditary risk. The experiences of the cohorts were simulated from birth to age six. The target population, risk reduction, formula feeding and duration, and age-specific AD incidence were selected on the basis of the GINI. ${ }^{14,19}$

The analysis adopted a societal perspective and included direct medical, indirect (time loss), and out of pocket (transportation) costs associated with the prevention and treatment of AD. The primary outcomes for each treatment arm included the proportion of patients developing $\mathrm{AD}$, the number of days with AD flare, the time spent post-AD diagnosis, quality adjusted life years (QALYs), and costs.

The simplified model structure is presented in Figure 1; urban infant cohorts entered the model at birth and were followed in bi-weekly cycles until age 6. Infants were initiated on CMF or PHF-W for the first 17 weeks of life (as in GINI) until 12 months of age or the development of AD. Similar to previous published models on this topic $24-26,28,30,31,34$, three treatment approaches were possible after initial development of AD, as confirmed by Indonesian pediatricians with AD treatment experience (authors AS and ZM). The first approach involved a switch in feeding formula, including a switch to extensively hydrolyzed formula (EHF), soy or amino acid. This approach was used among infants $\leq 12$ months presenting with mild $\mathrm{AD}$ (in $100 \%$ of cases) or moderate AD (in 50\% of cases). The second approach included pharmacological therapies and 


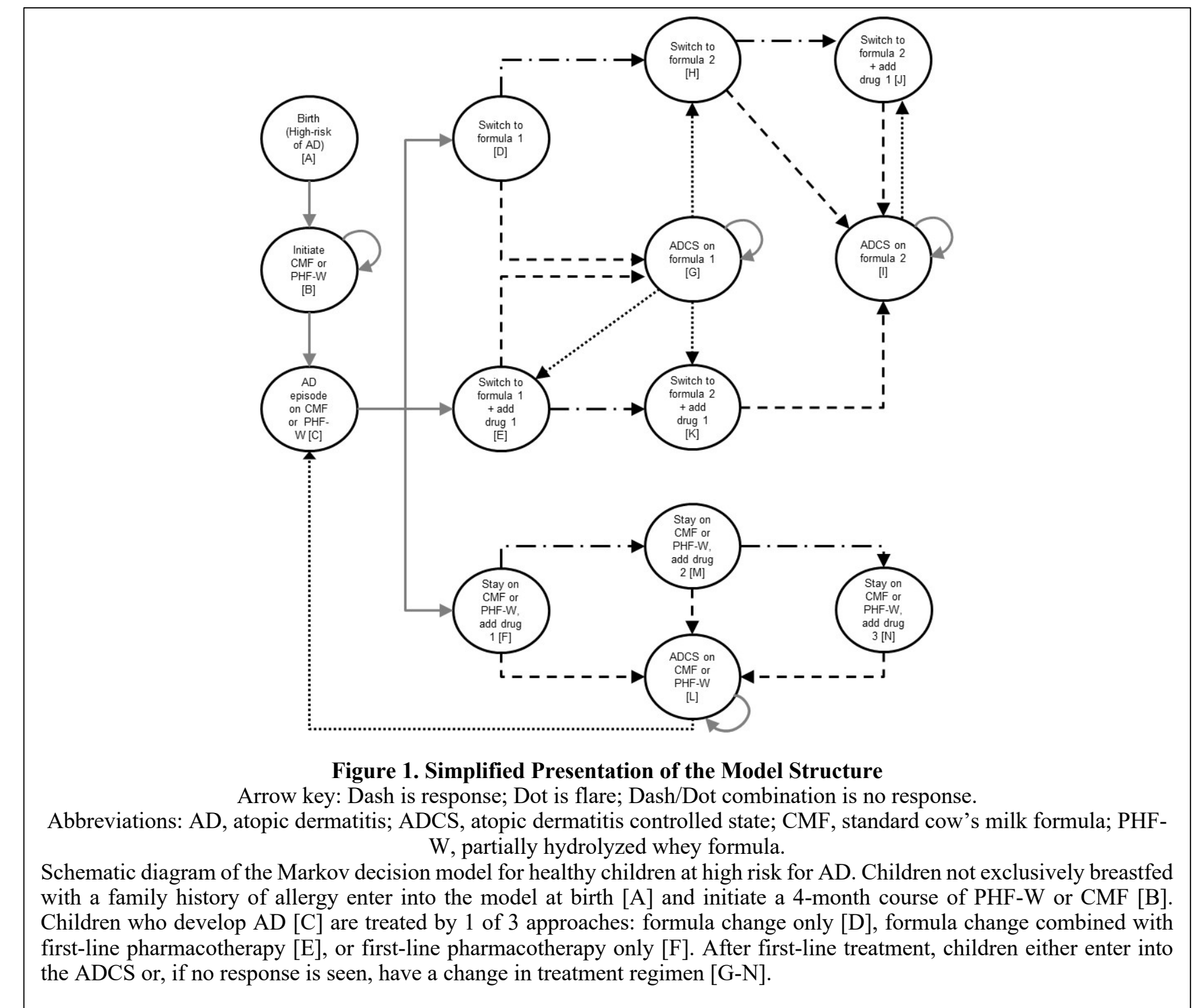

was used among all children $>12$ months regardless of severity at presentation. The third approach combined both changes in formula and pharmacological therapies and was used in $50 \%$ of infants $\leq 12$ months presenting with mild AD and in all infants $\leq 12$ months presenting with severe AD. Any infant formula use was assumed to end at 12 months of age as nutrient requirements shift to solid foods by this age; hence, the pharmacological treatment is the only treatment pathway available post 12 months of age. If a child was treated with a formula switch and responded favorably, she/he was assumed to continue on that new formula until (a) reaching 12 months of age, (b) the next $\mathrm{AD}$ episode (i.e., flare), or (c) death. If a child was treated with pharmacotherapy, she/he was assumed to continue treatment until completion of the recommended course and remain on his/her initial formula.

Treatment success was assessed every two weeks and was defined by a resolution of $\mathrm{AD}$ symptoms. Response rates determined the distribution of children who experience $\mathrm{AD}$ symptom resolution and hence the proportion of children transitioning to from the initial AD episode into a so-called "AD-controlled state" (ADCS). Response rates varied according to $\mathrm{AD}$ severity, treatment approach, and the line of treatment.

Finally, a child could experience subsequent relapse(s) (i.e., flare[s]) following period(s) of ADCS as determined based upon age and AD severity. 


\section{Inputs}

Epidemiologic inputs are provided in Table 1. Probability of initial AD development and subsequent flares obtained from the GINI study ${ }^{14}$ were stratified by severity (i.e., mild, moderate, and
Daily formula intake was age adjusted for nutrient needs from birth to 12 months by means of a previously-reported method ${ }^{25}$ that accounted for partial breast feeding. Formula acquisition costs (IDR 129,000 for a 400g can of PHF-W; IDR 91,800 for a $650 \mathrm{~g}$ can of CMF; IDR 167,139 for a $400 \mathrm{~g}$ can

Table 1. Epidemiologic Inputs

\begin{tabular}{|c|c|c|c|c|}
\hline & \multirow{2}{*}{ Base Case } & \multicolumn{2}{|c|}{ Value in uSA } & \multirow{2}{*}{ PSA Distribution } \\
\hline & & Low & High & \\
\hline \multicolumn{5}{|c|}{ Probability of AD: CMF $\$$} \\
\hline 0 to 1 year & $16.80 \%$ & $6.96 \%$ & $29.85 \%$ & Beta \\
\hline 1 to 3 years & $20.07 \%$ & $9.00 \%$ & $34.19 \%$ & Beta \\
\hline 3 to 6 years & $8.42 \%$ & $0.18 \%$ & $29.66 \%$ & Beta \\
\hline \multicolumn{5}{|c|}{ RR of AD (cumulative) (PHF-W vs. CMF) $\ddagger$} \\
\hline 0 to 1 year & 0.54 & 0.33 & 0.89 & Lognormal \\
\hline 1 to 3 year & 0.57 & 0.36 & 0.90 & Lognormal \\
\hline 3 to 6 year & 0.82 & 0.40 & 1.70 & Lognormal \\
\hline \multicolumn{5}{|c|}{$\begin{array}{l}\text { Distribution of cases by severity at initial } \\
\text { presentation: } 0-1 \text { years } \S\end{array}$} \\
\hline Mild AD & $50.00 \%$ & $46.20 \%$ & $53.80 \%$ & Beta \\
\hline Moderate AD & $40.00 \%$ & $46.67 \%$ & $32.91 \%$ & Beta \\
\hline Severe AD & $10.00 \%$ & $7.13 \%$ & $13.28 \%$ & Beta \\
\hline \multicolumn{5}{|c|}{$\begin{array}{l}\text { Distribution of cases by severity at initial } \\
\text { presentation: }>1 \text { years } \S\end{array}$} \\
\hline Mild AD & $60.00 \%$ & $56.05 \%$ & $63.88 \%$ & Beta \\
\hline Moderate AD & $30.00 \%$ & $36.81 \%$ & $22.83 \%$ & Beta \\
\hline Severe AD & $10.00 \%$ & $7.13 \%$ & $13.28 \%$ & Beta \\
\hline \multicolumn{5}{|c|}{$\begin{array}{l}\text { Probability of flare recurrence over } 12 \text { weeks: } \\
0-1 \text { years } \$\end{array}$} \\
\hline Mild AD & $30.00 \%$ & $24.83 \%$ & $35.44 \%$ & Beta \\
\hline Moderate AD & $50.00 \%$ & $39.99 \%$ & $60.01 \%$ & Beta \\
\hline Severe AD & $75.00 \%$ & $33.41 \%$ & $98.53 \%$ & Beta \\
\hline \multicolumn{5}{|c|}{$\begin{array}{l}\text { Probability of flare recurrence over } 12 \text { weeks: } \\
>1 \text { years } \S\end{array}$} \\
\hline Mild AD & $10.00 \%$ & $8.39 \%$ & $11.74 \%$ & Beta \\
\hline Moderate AD & $30.00 \%$ & $24.83 \%$ & $35.44 \%$ & Beta \\
\hline Severe AD & $50.00 \%$ & $39.99 \%$ & $60.01 \%$ & Beta \\
\hline Mortality \| & $0.0310 \%$ & & & \\
\hline
\end{tabular}

Abbreviations: $\mathrm{AD}$, atopic dermatitis; $\mathrm{CMF}$, standard cow's milk formula; PHF-W, partially-hydrolyzed whey-based formula; PSA, probabilistic sensitivity analysis; RR, relative risk; uSA, univariate sensitivity analyses.

+ Source: von Berg et al. 2008 for PHF-W vs. CMF ${ }^{14}$

$\S$ Source: Expert panel

\| Source: Mortality data for children under 5 (Source: World Bank data)

severe) and age (i.e., 0-1 years; $>1-6$ years). The biweekly probabilities of AD for PHF-W and CMF were obtained using linear interpolation of the 1,3 , and 6 year cumulative incidence data from the GINI study. ${ }^{14}$ Table 2 provides the clinical management and treatment effectiveness inputs, including $\mathrm{AD}$ management modalities and response rates by $\mathrm{AD}$ severity, treatment line, and age group. of soy; 417,000 for 400g of EHF; and 490,000 for $400 \mathrm{~g}$ of amino acid) were based on the price and market share in Indonesia (Source: Packaged Food: Euromonitor from trade sources/national statistics, February 2013). Recommended quantities from the package inserts were used to determine quantity of formula for daily consumption. The analysis took into account the additional, incremental cost that 
Table 2. Clinical Management and Effectiveness Inputs

\begin{tabular}{|c|c|c|c|c|}
\hline \multirow{2}{*}{ Variable } & \multirow{2}{*}{$\begin{array}{l}\text { Base } \\
\text { Case }\end{array}$} & \multicolumn{2}{|c|}{ Value in uSA } & \multirow{2}{*}{$\begin{array}{c}\text { PSA } \\
\text { Distribution } \\
\end{array}$} \\
\hline & & Low & High & \\
\hline Response rate to change of formula in PHF-W cohort & $50 \%$ & $40 \%$ & $60 \%$ & Beta \\
\hline Response rate to change of formula in CMF cohort & $80 \%$ & $18 \%$ & $100 \%$ & Beta \\
\hline \multicolumn{5}{|l|}{ Response rate to combination treatment } \\
\hline 1 st-line Moderate AD & $70 \%$ & $19 \%$ & $99 \%$ & Beta \\
\hline 2rd-line Moderate AD & $70 \%$ & $19 \%$ & $99 \%$ & Beta \\
\hline 3rd-line Moderate AD & $70 \%$ & $19 \%$ & $99 \%$ & Beta \\
\hline 1 st-line Severe AD & $55 \%$ & $43 \%$ & $67 \%$ & Beta \\
\hline 2nd-line Severe AD & $55 \%$ & $43 \%$ & $67 \%$ & Beta \\
\hline 3rd-line Severe AD & $55 \%$ & $43 \%$ & $67 \%$ & Beta \\
\hline \multicolumn{5}{|l|}{ 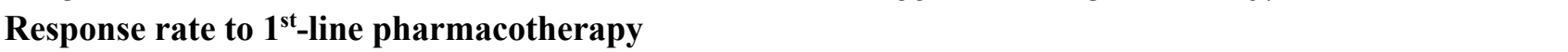 } \\
\hline Mild AD & $100 \%$ & $100 \%$ & $100 \%$ & NA \\
\hline Moderate AD & $50 \%$ & $40 \%$ & $60 \%$ & Beta \\
\hline Severe AD & $50 \%$ & $40 \%$ & $60 \%$ & Beta \\
\hline \multicolumn{5}{|l|}{ Response rate to $2^{\text {nd }}$-line pharmacotherapy } \\
\hline Mild AD & $85 \%$ & $51 \%$ & $100 \%$ & NA \\
\hline Moderate AD & $90 \%$ & $66 \%$ & $100 \%$ & Beta \\
\hline Severe AD & $90 \%$ & $66 \%$ & $100 \%$ & Beta \\
\hline
\end{tabular}

Abbreviations: AD, atopic dermatitis; CMF, standard cow's milk formula; PHF-W, partially-hydrolyzed whey-based formula; PSA, probabilistic sensitivity analysis; uSA, univariate sensitivity analyses.

Source: Expert panel

would be incurred as a result of feeding with alternative infant formula (such as PHF-W, soybased formula, and EHF).

The two experts (authors AS and ZM) provided assumptions on the type and amount of resources used with each treatment modality based on severity of AD (Table 3). Table 3 also provides costs information. For inpatient/outpatient visits and diagnostic tests, average fees charged in Indonesian hospitals or laboratories where information was available were used. Emollients and or moisturizer creams were utilized by all AD patients both during and between flares. Pharmacotherapies acquisition costs were obtained from an online drug information tool (http://www.mims.com/Indonesia) commonly used in Indonesia. To be conservative, the lowest available drug price was used if more than one option was available. Reduced productivity (i.e., indirect costs) included lost time to care of $\mathrm{AD}$ children following the initial physician visit (4 hours) and 2 hours per visit thereafter. Transportation costs to and from each physician visits were also included in the analysis.

Based on previously published data, young children who do not have AD were assumed to experience a utility of 1.000 , but that those in ADCS after an episode had a utility of 0.980 to recognize that mild, subclinical episodes could permanently reduce QoL. ${ }^{35,36}$ The utilities associated for a mild, moderate, and severe AD episodes were 0.863, 0.690 , and 0.450 , respectively. Death was associated with a utility of zero.

\section{Analysis}

Using the model structure and inputs as detailed, several incremental cost effectiveness ratios (ICERs) were computed to estimate the economic value of PHF-W vs. CMF. These outcomes included the incremental costs per AD case avoided, per day(s) with flare avoided, and QALY gained. In addition, the cost of $\mathrm{AD}$ per patient with $\mathrm{AD}$ (overall and per year) and the number of annual $A D$ visits per patient with $\mathrm{AD}$ were also derived from the model to allow comparisons of these values with previous published estimates, as a way to validate the present analysis. 
Table 3. Price and Quantities of Resources Used Treat AD by Severity at Presentation

\begin{tabular}{|c|c|c|c|c|}
\hline & \multirow{2}{*}{$\begin{array}{c}\text { Cost per } \\
\text { unit }^{\dagger}\end{array}$} & \multicolumn{3}{|c|}{ Use per AD patient } \\
\hline & & Mild & Moderate & Severe \\
\hline \multicolumn{5}{|l|}{ Number of physician visits $\S$} \\
\hline At diagnosis & 150,000 & \multicolumn{3}{|c|}{1.00 visit, regardless of severity } \\
\hline \multicolumn{5}{|l|}{ Follow up } \\
\hline$<12$ months of age & 150,000 & \multicolumn{3}{|c|}{$\begin{array}{l}1.00 \text { visit / month until month } 6,1.00 \text { visit / } \\
2 \text { months from month } 6 \text { to month } 12 \text {, all } \\
\text { regardless of severity }\end{array}$} \\
\hline$\geq 12$ months of age & 150,000 & \multicolumn{3}{|c|}{1.00 visit / 3 months, regardless of severity } \\
\hline \multicolumn{5}{|l|}{$\begin{array}{l}\text { Number of hospitalizations (at initial } \\
\text { diagnosis) } \S\end{array}$} \\
\hline Any age & 500,000 & 0.00 & 0.00 & 0.10 \\
\hline \multicolumn{5}{|l|}{$\begin{array}{l}\text { Number of diagnostic tests (at initial } \\
\text { diagnosis) } \S\end{array}$} \\
\hline Specific IgE test ( $\leq 3$ years) & 259,000 & 1.00 & 1.00 & 1.00 \\
\hline Skin prick test ( $>3$ years) & 425,000 & 1.00 & 1.00 & 1.00 \\
\hline \multicolumn{5}{|l|}{$\begin{array}{l}\text { Pharmacotherapy units per child with } \mathrm{AD} \text { (at } \\
\text { initial diagnosis and in case of flare or non- } \\
\text { response) } \$\end{array}$} \\
\hline Emollient cream (40 g/unit) & 80,000 & 3.00 & 3.00 & 3.00 \\
\hline Antibiotic oral $50 \mathrm{~mL}(<12$ months of age $)$ & 50,000 & 0.00 & 0.00 & 0.50 \\
\hline $\begin{array}{l}\text { Antibiotic oral } 300 \mathrm{mg} \times 30 \text { 's ( } \geq 12 \text { months of } \\
\text { age) }\end{array}$ & 326,345 & 0.00 & 0.00 & 0.50 \\
\hline Antibiotic Topical $2 \%$ x $10 \mathrm{~g}$ x 1's & 54,000 & 0.00 & 1.50 & 2.25 \\
\hline Antihistamines $5 \mathrm{mg}$ x 30 's & 110,000 & 0.00 & 0.50 & 0.75 \\
\hline Corticosteroid - oral $16 \mathrm{mg} \mathrm{x} 5 \times 6$ 's & 162,000 & 0.00 & 0.00 & 0.12 \\
\hline Corticosteroid - topical 10g x 1's (tube) & 54,500 & 0.00 & 1.00 & 1.50 \\
\hline Immunosuppressants $25 \mathrm{mg} \times 5 \times 10 \mathrm{~s}$ & 763,665 & 0.00 & 0.00 & 0.60 \\
\hline Pimecrolimus 1g x 1's (tube) & 139,125 & 0.00 & 0.00 & 1.00 \\
\hline Special wash care $100 \mathrm{~g}$ bar of soap (per flare) & 31,000 & 2.00 & 2.00 & 2.00 \\
\hline \multicolumn{5}{|l|}{ Other costs $\|$} \\
\hline Hours lost to attend initial care & 714.15 & 4.00 & 4.00 & 4.00 \\
\hline Hours lost per physician visit & 714.15 & 2.00 & 2.00 & 2.00 \\
\hline Trip per physician visit & 35,880 & 1.00 & 1.00 & 1.00 \\
\hline
\end{tabular}

Abbreviations: AD, atopic dermatitis; IDR, Indonesian Rupiah; IgE, immunoglobulin E

Source: Expert opinion.

$\uparrow$ Varied by $\pm 25 \%$ in univariate and multivariate sensitivity analyses (via uniform distributions).

+ Costs obtained from MIMS (http://www.mims.com/Indonesia/home/Index).

$\S$ Costs are based on average fees charged in Indonesia.

$\|$ Costs associated with the time loss were estimated using average hourly wages in Indonesia, labor force participation, and hours spent was obtained from the expert panel and is based on their experience of treating AD patients.

Sensitivity analyses evaluated the robustness of the results. Univariate sensitivity analyses (uSA) varied individual model parameters while keeping other base-case values unchanged (see Tables 1-3 for ranges). Scenario analyses were conducted to test the impact of changing key model assumptions either alone or in combination. These included omitting any flares from the analysis and restricting the analysis to 1 year (as opposed to the 6-year time frame). Multivariate, probabilistic sensitivity analysis (PSA) was conducted whereby the models were run 5,000 times via the Monte Carlo simulation to estimate so-called bootstrapped 95\% "credible intervals" (95\% CIs).

In accordance with common health economics research guidelines, clinical and economic outcomes occurring after the first year were discounted at $3 \%$ per annum to estimate the net 
present value of the different strategies, to reflect society's preference for the present. All costs reported in this study represent 2013 values, expressed in Indonesian Rupiah (IDR) (IDR100,000=USD7.58 as of May 12, 2015).

\section{Results}

$\mathrm{CMF}$ was associated with higher $\mathrm{AD}$ incidence $(+14 \%)$ compared to PHF-W (CMF 39\% vs. PHF$\mathrm{W} 25 \%$ ), less AD days (58 vs. 96), and fewer years $(-0.69)$ in a post-AD diagnosis state (1.69 vs. 1.00$)$. Discounted QALYs were 5.454 with PHF-W versus 5.500 for CMF, for a net difference of 0.046 (Table 4). All differences were predicted to be significant on the basis of the PSA, as indicated by the $95 \%$ CI (Table 4).
The total discounted costs (direct and indirect) among the non-exclusively breastfed infants with atopic heredity were lower among those fed with PHF-W formula (IDR 8,695,057; or USD659) compared to those in the CMF group (IDR $13,139,569$; or USD996). Primary drivers of total costs were those associated with pharmacological treatments followed by indirect costs and physician visits. The resulting 6-year net savings due to risk reduction of AD with PHF-W was IDR 4,445,512 (USD337) (Table 4). Comparison of PHF-W versus CMF using ICER values showed PHF-W to be a net cost saving strategy that also resulted in reductions of $\mathrm{AD}$ cases and gains in AD-free days and QALYs. Thus, PHF-W was the "dominant" strategy (i.e., more effective and less expensive) relative to CMF (Table 4).

Table 4. Results

\begin{tabular}{|c|c|c|c|}
\hline & PHF-W arm & CMF arm & Difference \\
\hline \multicolumn{4}{|l|}{ Discounted Costs (IDR) } \\
\hline Formula prevention & 783,291 & -- & 783,291 \\
\hline Formula treatment & 495,843 & 674,119 & $-178,276$ \\
\hline Physician visits & 334,329 & 563,353 & $-229,025$ \\
\hline Pharmacotherapy & $6,928,005$ & $11,655,352$ & $-4,727,347$ \\
\hline Diagnostic testing & 68,903 & 104,210 & $-35,307$ \\
\hline Hospitalization & 1,196 & 1,886 & -690 \\
\hline Indirect costs & 83,491 & 140,649 & $-57,158$ \\
\hline & $8,695,057$ & $13,139,569$ & $-4,444,512$ \\
\hline Total costs $(95 \% \mathrm{CI}) \ddagger$ & $\begin{array}{l}(4,519,447 \\
13,995,605)\end{array}$ & $(7,098,794,19,216,068)$ & $\begin{array}{l}(-8,557,946,- \\
893,080)\end{array}$ \\
\hline Discounted Costs (in USD) & USD 659 & USD 996 & -USD 337 \\
\hline \multicolumn{4}{|l|}{ Clinical effects } \\
\hline Proportion of children developing AD & $25 \%$ & $39 \%$ & $-14 \%$ \\
\hline$(95 \% \mathrm{CI})+$ & $(0.13,0.43)$ & $(0.23,0.54)$ & $(-0.23,-0.04)$ \\
\hline Years of life post AD diagnosis $(95 \%$ & 1.00 & 1.69 & -0.69 \\
\hline $\mathrm{CI})+$ & $(0.56,1.67)$ & $(1.04,2.43)$ & $(-1.13,-0.26)$ \\
\hline Days with AD symptoms $(95 \% \mathrm{CI}) \ddagger$ & $\begin{array}{c}58 \\
(29,95)\end{array}$ & $\begin{array}{c}96 \\
(53,142)\end{array}$ & $\begin{array}{c}-38 \\
(-67,-12)\end{array}$ \\
\hline Discounted QALYs $(95 \% \mathrm{CI}) \ddagger$ & $\begin{array}{c}5.500 \\
(5.418,5.537)\end{array}$ & $\begin{array}{c}5.454 \\
(5.332,5.514)\end{array}$ & $\begin{array}{c}0.046 \\
(0.014,0.103)\end{array}$ \\
\hline \multicolumn{4}{|l|}{ ICER (Discounted) } \\
\hline Cost per AD-case avoided & & & Dominant $\S$ \\
\hline Cost per AD-free day gained & & & Dominant $\S$ \\
\hline Cost per QALY gained & & & Dominant $\S$ \\
\hline
\end{tabular}

Abbreviations: AD, atopic dermatitis; IDR, Indonesian Rupiah; CMF, standard cow's milk formula; PHF-W, partiallyhydrolyzed whey-based formula; QALY, quality adjusted life-year.

Base-case results are presented in the table above for an average healthy formula-fed infant with a positive family history of allergy (high-risk of developing AD).

$\$$ Percentile distributions $\left(2.5^{\text {th }}\right.$ and $\left.97.5^{\text {th }}\right)$ for the parameters selected to represent the uncertainty surrounding the mean value of the parameter.

$\S$ Dominance refers to a situation where one intervention (PHF-W in this study) is said to dominate another (CMF in this study) when its effectiveness is found to be higher and the costs lower. 
PSA also indicated that PHF-W was dominant in almost all 5,000 model runs (Figure 2).In uSA, the relative risk of $\mathrm{AD}$ between $\mathrm{PHF}-\mathrm{W}$ and $\mathrm{CMF}$, and the probability of $\mathrm{AD}$ with $\mathrm{CMF}$, had the largest direct costs alone). The total annual number of visits per AD case was estimated to be approximately 2.47 (across all severity levels).

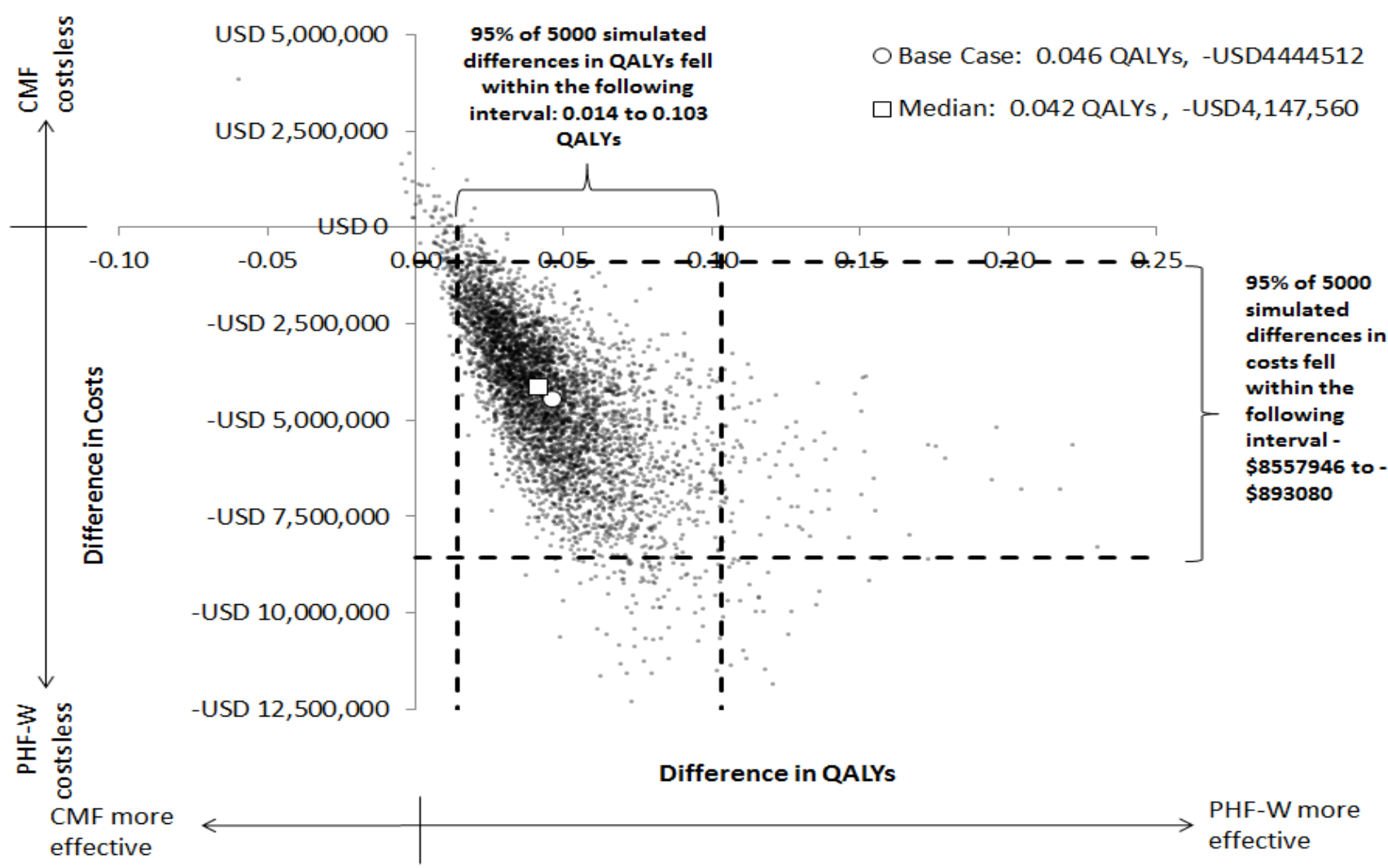

Figure 2. Scatterplot of Difference in Costs and QALYs Resulting from Multivariate PSA Each black dot represents 1 of the 5000 multivariate PSA simulations.

influence on the difference in cost between PHF-W and CMF. Other variables with potentially minor effect on net cost savings were the costs of PHF-W, $\mathrm{CMF}$, and emollients. Finally, in one scenario analysis, it was conservatively assumed that no AD patient would experience a recurrence. In that case, PHF-W remained cost dominant (i.e., resulting in a net discounted cost saving of IDR 3,545,058, 3 additional AD-symptom-free days, and discounted QALY gains of 0.014).

Finally, AD development at any time within the first 6 years of life was predicted to result in an undiscounted total (direct and indirect) AD cost of approximately IDR 35,600,000 (i.e., USD2,700) over this period. The estimated average annualized undiscounted total (direct and indirect) cost for an infant developing AD at any time within the first 6 years of life was approximately IDR 8,500,000 (i.e., USD645) (including IDR 8,443,175 [USD640] in

\section{Discussion}

This model shows that an early nutritional intervention with PHF-W in urban and nonexclusively breastfed Indonesian infants with firstdegree atopic heredity offers favorable AD risk reduction, fewer AD days with flare, and more QALYs compared to CMF while reducing costs. The robustness of these results was confirmed via sensitivity analyses.

The cost differential between the two formulas was driven by the incidence of AD in each arm and the costs associated with pharmacotherapy. Other variables and costs had minimal impact. The cost of pharmacotherapy was high because it was the most common and expensive treatment method. In a study reviewing awareness and practice of $\mathrm{AD}$ management among 255 dermatologists in Southeast Asian countries, pharmacotherapy had a 
high rate of use in all countries (i.e., Philippines, Vietnam, Thailand, Malaysia, Singapore, and Indonesia) reviewed. ${ }^{37}$ Moisturizers were used frequently, with over $79 \%$ of respondents in Indonesia having used moisturizers in any given phase of treatment, ${ }^{37}$ consistent with the use of emollients assumed in this analysis.

This analysis was limited by a lack of published data on Indonesia AD epidemiology and treatment patterns in at risk urban infants with first degree AD heredity. The impact of PHF-W and $\mathrm{CMF}$ on $\mathrm{AD}$ incidence has also not been specifically studied in urban Indonesian infants. Consequently, we relied on the results of GINI ${ }^{14}$ as the best source of data given its standing as the largest and longest intervention trial on PHF-W and CMF to date. ${ }^{20,38}$ The cumulative $\mathrm{AD}$ incidence rates observed in GINI for PHF-W and CMF are also consistent with, if not perhaps more conservative than, those observed in a smaller Southeast Asian study by Chan et al, $2002(\mathrm{~N}=110)$ in genetically predisposed Singaporean infants. ${ }^{39}$ Specifically, cumulative AD incidence in the CMF and PHF-W arms at 24 months of age in this Southeastern Asian study was $43.9 \%$ and $22.6 \%$, respectively (an absolute difference of 21.3 percentage points; odds ratio $=0.37, \mathrm{P}=0.019) .{ }^{39}$ Corresponding rates in GINI were $33.5 \%$ and $19.4 \%$, respectively (an absolute difference of 14 percentage points; adjusted $\mathrm{RR}=0.57,95 \%$ CI: 0.36-0.90). ${ }^{14}$

Little evidence is available regarding the severity of $\mathrm{AD}$ in Indonesia and elsewhere. In the present analysis, it was assumed that $\mathrm{AD}$ would be moderate and severe in $40 \%$ and $10 \%$ of cases in children aged $<1$ year, respectively, and in $30 \%$ and $10 \%$ of cases in children aged 1-6 years, respectively. In the International Study of Asthma and Allergies in Childhood (ISAAC), ${ }^{40}$ severe AD (defined as current eczema associated with sleep disturbance 1 or more nights per week) accounted for $11 \%$ of $A D$ cases in those aged 6 to 7 years old. In a survey of knowledge, attitudes, and practices of Southeast Asian dermatologists in the management of $\mathrm{AD},{ }^{37}$ mild and moderate cases accounted for $65 \%$ and $35 \%$ of patients, respectively. Thus, the assumptions used herein may be considered reasonable given the population considered (i.e., high-risk urban infants - defined as those having $\geq 1$ parent or sibling with history of allergic disease/first degree atopic heredity). At the same time, it should be noted that the assumptions regarding both the severity and prevalence of $\mathrm{AD}$ may reflect the perspective adopted herein, which focuses on the urban, affluent population, which was expected to be most prone to use hydrolyzed infant formula. Thus, the outcomes of this analysis could have been substantially different had we adopted a rural or government practice perspective.

Treatment patterns and assumptions regarding $\mathrm{AD}$ treatment effectiveness once a child developed $\mathrm{AD}$ were derived largely from the clinical opinion of three Indonesian physicians, reflecting the relative lack of Indonesian data on AD severity. This reliance on expert opinion is an important limitation of--but is not unique to--the present analysis. For instance, other cost-effectiveness analyses of hydrolyzed formula in Western countries $^{24-30}$ have relied upon similar data collection methods and evidence standards adopted herein. In part, the reliance on expert opinion is dictated by the clinical diagnosis of $\mathrm{AD}$ and its subjective assessment of severity. Furthermore, AD diagnosis and management are not routinely recorded administratively for reimbursement purposes. Hence many AD treatments require outof-pocket expenditure borne by families. These may be under-recorded and are difficult to estimate.

Despite these important limitations, it should be noted that the annual costs of AD IDR 8,500,000 (i.e., USD645) are within a comparable range of estimates found in other developing Asian countries such as Thailand (USD199 for direct cost), ${ }^{9}$ Malaysia (USD584 overall and USD398 in direct costs), ${ }^{41}$ the Philippines (USD359), ${ }^{31}$ or a recent estimate of annual treatment costs in patients aged 7 years in low-income Asian countries including Indonesia (ranging from USD640 to USD929 depending on the emollient used). ${ }^{42}$ While not directly comparable due to difference in income per capita, it is worth noting that the present estimates are not surprisingly much lower than estimates from higher income countries such as Singapore (USD1,212 including USD1,007 in direct costs alone), ${ }^{43}$ Australia (total costs: USD6,187, direct cost: USD4,842; AD patients from a dermatology clinic), ${ }^{6}$ or South Korea (total cost: USD3,522, direct cost: USD1,253; patients from an allergy clinic) ${ }^{10}$ (all figures inflated to 2012-2013 and converted to USD). These differences reflect variations in study design and methods, target patient populations, treatment patterns and percapita income. 
The average number of physician visits per year needed for AD management (2.47) appears conservative compared with data from Thailand (approximately 4 to 5 visits overall) ${ }^{9}$ and in analyses similar to this one conducted for Singapore $(3.51)^{43}$ and Malaysia (6.88). ${ }^{41}$

The relative consistency of present study's estimates of both the annual cost of, and number of visits associated with, $\mathrm{AD}$ with previous research in lower income Asian countries as described above provide some reassurance that our estimates of the benefits of preventing $\mathrm{AD}$ with hydrolyzed infant formula are likely relatively robust despite uncertainty regarding $\mathrm{AD}$ treatment patterns in Indonesia.

In some ways, one might consider that the present study is conservative in a number of aspects. First, incidence and effects of $\mathrm{AD}$ were exclusive within to the first 6 years of life only; given the chronic nature of $\mathrm{AD}$, further burden is possible. Secondly, PHF-W could also have a protective effect to other allergic manifestations; impact of which is not captured here. Lastly, details on the impact on parents' productivity and quality of life (as a result of poor night sleep to attend a crying child, etc.) was not captured in its entirety due to lack of data; compounded with the potential impact of AD of QoL could result in further additional cost savings to be realized.

In conclusion, this model showed the longterm cost-effectiveness of PHF-W nutritional intervention versus CMF in healthy urban infants with atopic heredity (high-risk) who are not exclusively breastfed from an Indonesian perspective. Results suggests that the use of PHF-W is superior to $\mathrm{CMF}$ as it reduces the clinical and $\mathrm{QoL}$ burden of AD while decreasing overall costs, even after the inclusion of formula costs. These results will be important to note by key payers in making decisions regarding reimbursement/coverage policies for formulas among at-risk urban infants.

\section{Abbreviations}

$\mathrm{AD}$, atopic dermatitis; ADCS, AD-controlled state; CMF, standard cow's milk formula; CI, credible interval; EHF, extensively hydrolyzed formula; GINI, German Infant Nutritional Intervention; IDR, Indonesian Rupiah; ICER, incremental cost effectiveness ratio; ISAAC, International Study of Asthma and Allergies in Childhood; PHF-W, partially-hydrolyzed whey-based formula; PSA, probabilistic sensitivity analysis; QALY, quality adjusted life year; QoL, quality of life; RR, relative risk; uSA, univariate sensitivity analyses; USD, United States dollars

\section{Conflict of Interest}

Pharmerit International ("Pharmerit") received partial research funding from the Nestlé Nutrition Institute in Vevey, Switzerland to conduct this study. Abhijeet J. Bhanegaonkar, Xiang Ji, and Wing Yu Tang were employees of Pharmerit. Erica G. Horodniceanu is an employee of Pharmerit. Marc F. Botteman is co-founder and managing partner of Pharmerit. Nestlé Research Center in Lausanne, Switzerland, funded this study. Ray Wagiu Basrowi is an employee of Nestlé Nutrition Institute, Indonesia and PT Nestlé Indonesia. Patrick Detzel is an employee of Nestlé Research Center. The Nestlé Research Center in Lausanne is part of Nestlé. Nestlé NAN HA ${ }^{\circledR}$, one of the products evaluated in this study, is manufactured and commercialized by Nestlé. Pharmerit retained independent control of the methodology and presentation of results for this study.

\section{Open Access}

This article is distributed under the terms of the Creative Commons Attribution 4.0 International Licence(http://creativecommons.org/licenses/by/4.0 ), which permits unrestricted use, distribution, and reproduction in any medium, provided you give appropriate credit to the original author(s) and the source, provide a link to the Creative Commons license, and indicate if changes were made.

\section{Author contributions}

All authors contributed to this research and manuscript and provided final approval for publication. MF led the study design, model design, determination of model inputs, data analysis, interpretation of results and findings, and the writing of the manuscript. ZM and AWS provided clinical input, validated model assumptions, and were involved in the review and revision of the manuscript. EH and WT contributed to the literature review, data collection, identification of model inputs, and writing and finalizing of the manuscript. 
$\mathrm{AB}$ and $\mathrm{XJ}$ contributed to the model design, data analysis, and the reporting of results. RWB contribute in local market and healthcare data and was involved in review and revision of the manuscript. PD initiated the study and provided oversight and guidance on the model design, inputs, and analysis, and was involved in review and revision of the manuscript.

\section{References}

1. Spergel JM, Paller AS. Atopic dermatitis and the atopic march. The Journal of allergy and clinical immunology 2003;112. [Google Scholar]

2. Catherine Mack Correa M, Nebus J. . Management of patients with atopic dermatitis: the role of emollient therapy. Dermatology research and practice 2012; 2012. [Google Scholar]

3. Lewis-Jones S. Quality of life and childhood atopic dermatitis: the misery of living with childhood eczema. International journal of clinical practice 2006;60:984-92. [Google Scholar]

4. Asher MI, Montefort S, Bjorksten B, Lai CK, Strachan DP, Weiland SK, et al. Worldwide time trends in the prevalence of symptoms of asthma, allergic rhinoconjunctivitis, and eczema in childhood: ISAAC Phases One and Three repeat multicountry cross-sectional surveys. Lancet 2006;368:733-43. [Google Scholar]

5. Aziah MS, Rosnah T, Mardziah A, Norzila MZ. Childhood atopic dermatitis: a measurement of quality of life and family impact. The Medical journal of Malaysia 2002;57:329-39. [Google Scholar]

6. Su JC, Kemp AS, Varigos GA, Nolan TM. Atopic eczema: its impact on the family and financial cost. Archives of disease in childhood 1997;76:159-62. [Google Scholar]

7. Williams H, Stewart A, Mutius, E. von , Cookson W, Anderson HR. International Study of Asthma and Allergies in Childhood (ISAAC) Phase One and Three Study Groups. Is eczema really on the increase worldwide. The Journal of allergy and clinical immunology 2008;121:947-54. [Google Scholar]
8. Anggraeni $\mathrm{M}$, Wati KDK, Tangking $\mathrm{K}$. Using family atopy scores to identify the risk of atopic dermatitis in infants. Paediatr Indones 2014;54:331. [Google Scholar]

9. Ngamphaiboon J, Kongnakorn T, Detzel P, Sirisomboonwong K, Wasiak R. Direct medical costs associated with atopic diseases among young children in Thailand. Journal of medical economics 2012;15:1025-35. [Google Scholar]

10. Kang KH, Kim KW, Kim DH. Utilization Pattern and Cost of Medical Treatment and Complementary Alternative Therapy in Children with Atopic Dermatitis. Pediatric Allergy and Respiratory Disease 2012;22:27-36. [Google Scholar]

11. Halken S, Host A, Hansen LG, Osterballe O. Effect of an allergy prevention programme on incidence of atopic symptoms in infancy. A prospective study of 159 "high-risk" infants. Allergy 1992;47:545-53. [Google Scholar]

12. Host A, Halken S, Muraro A, Dreborg S, Niggemann B, Aalberse R, et al. Dietary prevention of allergic diseases in infants and small children. Pediatr Allergy Immunol 2008;19:1-4. [Google Scholar]

13. World Health Organization. Infant and young child nutrition. Global strategy on infant and young child feeding. Report by the Secretariat. Fifty-fifth World Health Assembly2002 April 16. Report No.: A55/15. Provisional agenda item 13.10.

14. Berg, A. von , Filipiak-Pittroff B, Kramer U, Link E, Bollrath C, Brockow I, et al. Preventive effect of hydrolyzed infant formulas persists until age 6 years: long-term results from the German Infant Nutritional Intervention Study (GINI. The Journal of allergy and clinical immunology 2008;121:1442-7. [Google Scholar]

15. Berg, A. von, Filipiak-Pittroff B, Kramer U, Hoffmann B, Link E, Beckmann C, et al. Allergies in high-risk schoolchildren after early intervention with cow's milk protein hydrolysates: 10-year results from the German Infant Nutritional Intervention (GINI) study. The Journal of allergy and clinical immunology 2013;131:1565-73. [Google Scholar] 
16. Greer FR, Sicherer SH, Burks AW, Immunology, o.N.a.S.o.A.a. (Committee) . Effects of early nutritional interventions on the development of atopic disease in infants and children: the role of maternal dietary restriction, breastfeeding, timing of introduction of complementary foods, and hydrolyzed formulas. Pediatrics 2008;121:183-91. [Google Scholar]

17. Hays T, Wood RA. A systematic review of the role of hydrolyzed infant formulas in allergy prevention. Archives of pediatrics \& adolescent medicine 2005;159:810-6. [Google Scholar]

18. Jin YY, Cao RM, Chen J, Kaku Y, Wu J, Cheng Y, et al. Partially hydrolyzed cow's milk formula has a therapeutic effect on the infants with mild to moderate atopic dermatitis: a randomized, double-blind study. Pediatr Allergy Immunol 2011;22:688-94. [Google Scholar]

19. Berg, A. von, Koletzko S, Grubl A, FilipiakPittroff B, Wichmann HE, Bauer CP, et al. The effect of hydrolyzed cow's milk formula for allergy prevention in the first year of life: the German Infant Nutritional Intervention Study, a randomized double-blind trial. The Journal of allergy and clinical immunology 2003;111:533-40. [Google Scholar]

20. Alexander DD, Cabana MD. Partially hydrolyzed $100 \%$ whey protein infant formula and reduced risk of atopic dermatitis: a meta-analysis. Journal of pediatric gastroenterology and nutrition 2010;50:422-30. [Google Scholar]

21. Host A, Koletzko B, Dreborg S, Muraro A, Wahn U, Aggett P, et al. Dietary products used in infants for treatment and prevention of food allergy. Joint Statement of the European Society for Paediatric Allergology and Clinical Immunology (ESPACI) Committee on Hypoallergenic Formulas and the European Society for Paediatric Gastroenterology, Hepatology and Nutrition (ESPGHAN) Committee on Nutrition. Archives of disease in childhood 1999;81:80-4. [Google Scholar]

22. Boyce JA, Assa'ad A, Burks AW, Jones SM, Sampson HA, Wood RA, et al. Guidelines for the diagnosis and management of food allergy in the United States: report of the
NIAID-sponsored expert panel. The Journal of allergy and clinical immunology 2010;126. [Google Scholar]

23. Fleischer DM, Spergel JM, Assa'ad AH, Pongracic JA. Primary prevention of allergic disease through nutritional interventions. $\mathrm{J}$ Allergy Clin Immunol: In Practice 2013;1:29-36. [Google Scholar]

24. Iskedjian M, Belli D, Farah B, Navarro V, Detzel P. Economic evaluation of a $100 \%$ whey-based partially hydrolyzed infant formula in the prevention of atopic dermatitis among Swiss children. Journal of medical economics 2012;15:378-93. [Google Scholar]

25. Iskedjian $M$, Dupont $C$, Spieldenner $J$, Kanny G, Raynaud F, Farah B, et al. Economic evaluation of a $100 \%$ wheybased, partially hydrolysed formula in the prevention of atopic dermatitis among French children. Current medical research and opinion 2010;26:2607-26. [Google Scholar]

26. Iskedjian M, Haschke F, Farah B, Odijk, J. van , Berbari J, Spieldenner J. Economic evaluation of a $100 \%$ whey-based partially hydrolyzed infant formula in the prevention of atopic dermatitis among Danish children. Journal of medical economics 2012;15:394408. [Google Scholar]

27. Iskedjian M, Szajewska H, Spieldenner J, Farah B, Berbari J. Meta-analysis of a partially hydrolysed $100 \%$-whey infant formula vs. extensively hydrolysed infant formulas in the prevention of atopic dermatitis. Current medical research and opinion 2010;26:2599-606. [Google Scholar]

28. Su J, Prescott S, Sinn J, Tang M, Smith P, Heine RG, et al. Cost-effectiveness of partially-hydrolyzed formula for prevention of atopic dermatitis in Australia. Journal of medical economics 2012;15:1064-77. [Google Scholar]

29. Mertens J, Stock S, Lungen M, Berg, A. von , Kramer U, Filipiak-Pittroff B, et al. Is prevention of atopic eczema with hydrolyzed formulas cost-effective? A health economic evaluation from Germany. Pediatr Allergy Immunol 2012;23:597-604. [Google Scholar] 
30. Spieldenner J, Belli D, Dupont C, Haschke $\mathrm{F}$, Iskedjian $\mathrm{M}$, Nevot Falco $\mathrm{S}$, et al. Partially hydrolysed $100 \%$ whey-based infant formula and the prevention of atopic dermatitis: comparative pharmacoeconomic analyses. Annals of nutrition \& metabolism 2011;59 Suppl 1:44-52. [Google Scholar]

31. Bhanegaonkar AJ, Horodniceanu EG, Gonzalez RRH, Mv CD, Detzel P, ErdoganCiftci E, et al. Cost-Effectiveness of Partially Hydrolyzed Whey Protein Formula in the Primary Prevention of Atopic Dermatitis in At-Risk Urban Filipino Infants. Value in Health Regional Issues 2014;3:124-35. [Google Scholar]

32. Beck JR, Pauker SG. The Markov process in medical prognosis. Medical decision making : An international journal of the Society for Medical Decision Making 1983;3:419-58. [Google Scholar]

33. Sonnenberg FA, Beck JR. Markov models in medical decision making: a practical guide. Medical decision making : An international journal of the Society for Medical Decision Making 1993;13:322-38. [Google Scholar]

34. He ECE, Botteman MF, Detzel P, Verheggen BG. Cost-effectiveness analysis of $100 \%$ whey-based partially hydrolyzed infant formula used for prevention of atopic dermatitis in Germany [abstr. Value in Health 2012;15(7). [Google Scholar]

35. Pitt M, Garside R, Stein K. A cost-utility analysis of pimecrolimus vs. topical corticosteroids and emollients for the treatment of mild and moderate atopic eczema. The British journal of dermatology 2006;154:1137-46. [Google Scholar]

36. Stevens KJ, Brazier JE, McKenna SP, Doward LC, Cork MJ. The development of a preference-based measure of health in children with atopic dermatitis. The British journal of dermatology 2005;153:372-7. [Google Scholar]

37. Chan YC, Tay YK, Sugito TL, Boediardja SA, Chau DD, Nguyen KV, et al. A study on the knowledge, attitudes and practices of Southeast Asian dermatologists in the management of atopic dermatitis. Annals of the Academy of Medicine, Singapore 2006;35:794-803. [Google Scholar]
38. Szajewska H, Horvath A. Meta-analysis of the evidence for a partially hydrolyzed $100 \%$ whey formula for the prevention of allergic diseases. Current medical research and opinion 2010;26:423-37. [Google Scholar]

39. Chan YH, Shek LP, Aw M, Quak SH, Lee BW. Use of hypoallergenic formula in the prevention of atopic disease among Asian children. Journal of paediatrics and child health 2002;38:84-8. [Google Scholar]

40. Odhiambo JA, Williams HC, Clayton TO, Robertson CF, Asher MI. Global variations in prevalence of eczema symptoms in children from ISAAC Phase Three. The Journal of allergy and clinical immunology 2009;124:1251-8. [Google Scholar]

41. Bhanegaonkar AJ, Horodniceanu EG, Ah AL, Woodhull S, Khoo PC, Detzel P, et al. Economic value of atopic dermatitis prevention via infant formula use in highrisk Malaysian infants. Asia Pac Allergy 2015;5:84-97. [Google Scholar]

42. Tang $\mathrm{M}$, Leong $\mathrm{K}$, Ou LS, Munasir Z, Parekh PR, Azmi S, et al. Cost-Effectiveness Study of Pediatric Atopic Dermatitis in Asia: Atopiclair vs. Regular Emollient (ADATOP. Journal of drugs in dermatology: JDD 2015;14:169-75. [Google Scholar]

43. Botteman MF, Bhanegaonkar AJ, Horodniceanu EG, Ji X, Lee BW, Shek LP, et al. Economic value of using partially hydrolysed infant formula for risk reduction of atopic dermatitis in high-risk, not exclusively breastfed infants in Singapore. Singapore medical journal 2018;59(8):439. [Google Scholar] 